\title{
Coulisses
}

Revue de théâtre

7| Printemps 1993

Varia

\section{Le théâtre, effet incantatoire d'éveil}

\section{Gilles Garbagnati}

\section{OpenEdition}

Journals

Édition électronique

URL : http://journals.openedition.org/coulisses/2171

DOI : 10.4000/coulisses. 2171

ISSN : 2546-9460

\section{Éditeur}

Presses universitaires de Franche-Comté

\section{Édition imprimée}

Date de publication : 1 avril 1993

Pagination : 14-17

ISSN : 1150-594X

\section{Référence électronique}

Gilles Garbagnati, « Le théâtre, effet incantatoire d'éveil », Coulisses [En ligne], 7 | Printemps 1993, mis en ligne le 15 mars 2019, consulté le 31 octobre 2019. URL : http://journals.openedition.org/coulisses/ 2171 ; DOI : 10.4000/coulisses. 2171

Ce document a été généré automatiquement le 31 octobre 2019

Coulisses 


\title{
Le théâtre, effet incantatoire d'éveil
}

\author{
Gilles Garbagnati
}

1 Guanikana ${ }^{1}$ ou le choc des Mondes, création collective en XI tableaux avec prologue et épilogue ${ }^{2}$, mise en scène Joseph Melcore.

2 Créé les 22 et 23 mai 1992 par 25 étudiants, salle Montjoye, dans le cadre du Colloque "Christophe Colomb et la découverte de l'Amérique, Mythe et Histoire ».

3 Repris et diffusé durant l'année 1993 avec 20 étudiants, le 6 février aux Sept jours du Thêâtre à l'université organisé par l'université de Bordeaux-III, le 29 février lors des 10 èmes Rencontres Internationales de Théâtre Universitaire de Liège, les 13 et 14 mars à Besançon Salle Montjoye au profit d'Amnesty International, le 17 mars pour la préinauguration du Théâtre de Giromagny (Territoire de Belfort), le 7 avril dans le cadre de la Semaine folle du Théâtre Universitaire de Dijon, le 17 avril à Grenoble pour le $1^{\text {er }}$ Festival National de Théâtre Etudiant de Grenoble, Ophelia.

Je viens parler par votre bouche morte.

Rassemblez à travers la terre

toutes vos silencieuses lèvres dispersées et de votre néant, durant toute cette

longue nuit

parlez-moi comme si j'étais ancré avec vous

racontez-moi tout, chaîne à chaîne maillon à maillon, pas à pas.... 


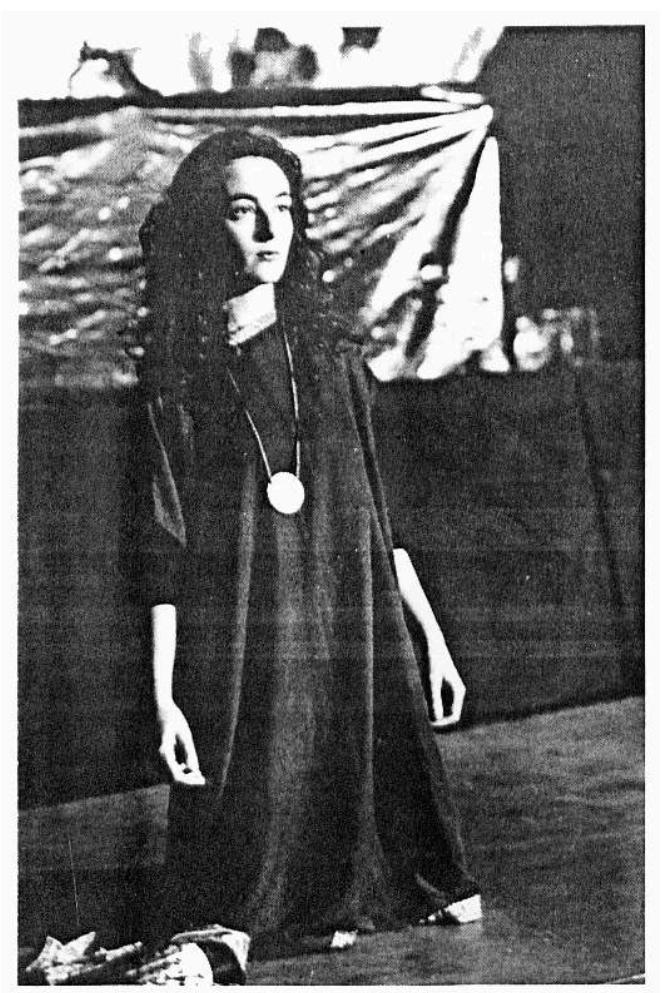

Bertrand PELLETIER

4 Depuis mai 1992, j'ai assisté personnellement à six représentations et à deux répétitions.

5 Mon intérêt pour la pièce tient à des raisons personnelles : je connais et apprécie le Théâtre Universitaire de Franche-Comté, et plus générales: je suis membre de l'association Terre des Hommes France qui en mai 1992 a été coordinatrice au niveau européen d'une campagne, qui a concerné plusieurs ONG de développement et a eu pour titre 500 ans de Résistance Indienne Noire et Populaire.

Il y a un recoupement évident entre les préoccupations de la campagne et le thème de Guanikana : la conquête espagnole vue par ses victimes.

7 J'ai d'ailleurs transmis le programme de la pièce et le compte-rendu de L'Est Républicain du 23/05/1992 à la coordinatrice de la Campagne.

8 Et depuis lors, le 16 octobre 1992 le Prix Nobel de la Paix a été attribué à Rigoberta Menchu, Indienne du Guatemala, du peuple Quiché. Sans être l'auteur de l'expression, depuis la mort de ses parents assassinés par le pouvoir légal, elle fait retentir « la voix indienne collective $»$.

9 Je ne parlerai que fort peu de Guanikana, en tant que performance théâtrale mais j'évoquerai les méditations que le spectacle a fait surgir en moi. Après tout, la valeur d'une création artistique réside dans l'effet incantatoire d'éveil qu'elle a sur son destinataire. 


\section{L'effet incantatoire d'éveil}

10 Les acteurs font ressentir le choc subi lors de la conquête : émerveillement des Indiens, souffrance devant la barbarie des intrus, puis résistance; les textes étant empruntés aux sources historiques écrites par les vaincus.

\section{Tableau 1}

Notre seigneur tu as souffert, la fatigue t'a accablé, maintenant tu as touché la terre, tu es arrivé à ta ville....

...Et tu es arrivé parmi les nuages, parmi les brumes

Et tout était comme nous l'avaient dit les Rois....

...Et maintenant, tout s'est accompli, tu es arrivé, ta fatigue est grande, tu es venu si volontiers....

\section{Guanikana}

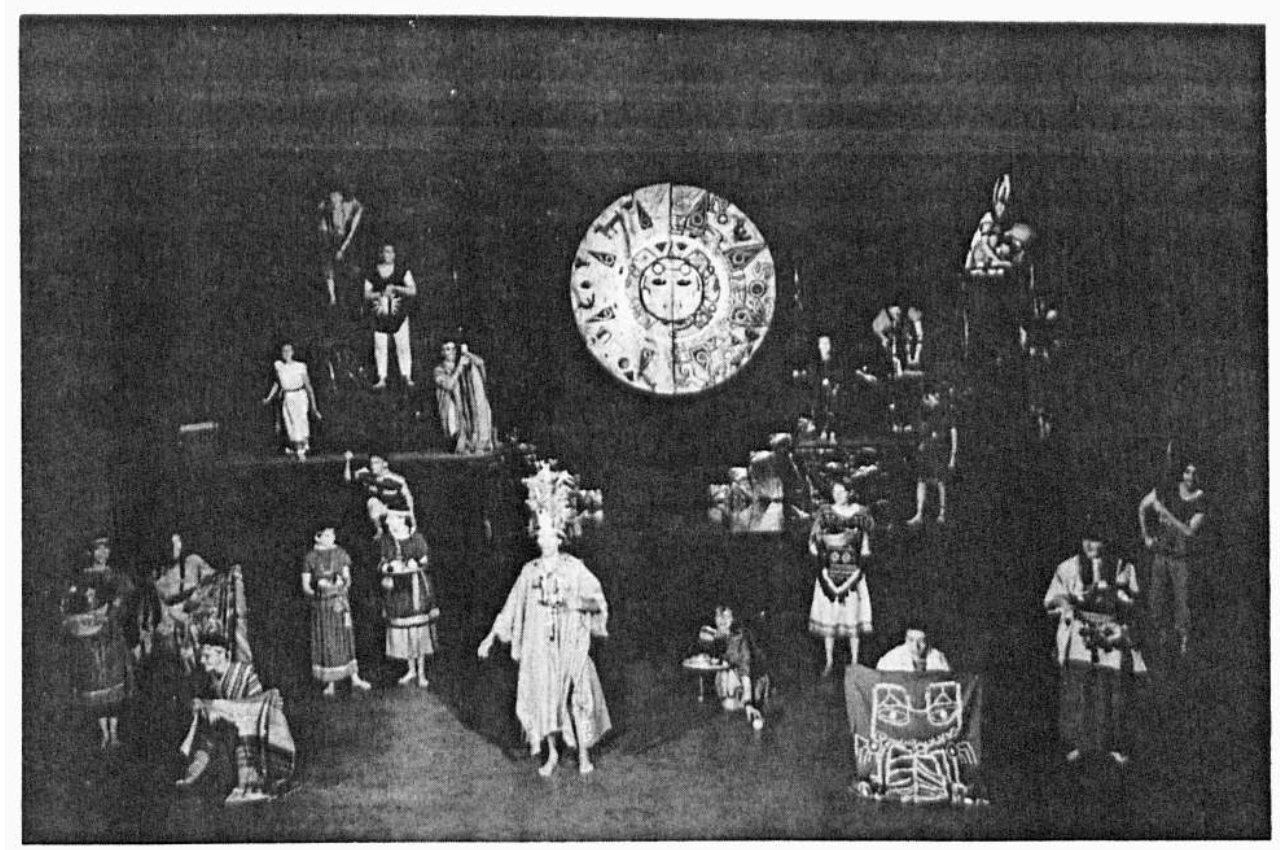

Bertrand PELLETIER

11 Et en stade final, le chœur de la voix indienne collective, celle de Léonard Peltier, Indien Sioux, le plus ancien prisonnier politique du monde, depuis la libération de Nelson Mandela et victime du F.B.I.

La pièce comporte une scène de sacrifice humain, présentée comme logique; historiquement en fait le choc des Mondes a joué dans l'autre sens : Cortez horrifié mais oubliant que dans son Espagne natale on brûlait les hérétiques, et non pour nourrir la force du Soleil.

L'une des femmes est vilipendée par ses compagnes pour avoir revêtu la défroque d'un Castillan mort. Ce n'est qu'un épisode. Ce personnage plus étoffé aurait pu être Malinche la compagne de Cortez, qui, a permis la victoire des conquérants. Elle est considérée avec mépris par les uns parce que elle est traitresse mais traitresse à qui ? Son peuple était menacé par l'expansionnisme aztèque, elle est regardée avec sympathie par d'autres comme symbole du lien entre les Mondes, baptisée Dona Marina. 
14 Ayant en mai 1992 assisté à une répétition, je me suis retrouvé ayant sur les lèvres la parole de Paul Claudel : Le pire n'est pas toujours sûr, sous-titre de la pièce Le Soulier de Satin.

Parmi les scénarios d'avenir imaginables, il n'est pas certain que le pire se réalisera. Et pour l'Histoire américaine dont Guanikana évoque le début, on peut reprendre ce mot. Le pire a failli se produire :

- En $1500: 80$ millions d'habitants en Amérique

- En 1550 : moins de 10 millions et bien moins cent ans plus tard.

Au lieu de 1500 et 1550 je prends des dates symboliques :

1) 20 décembre 1492 (au lieu de 1500) : arrivée de Christophe Colomb à Ayti.

2) 25 décembre 1553 (au lieu de 1550) : à Tucapel au Sud du Chili la grande armée de Valdiva était détruite. Le domaine des Conquérants avait atteint sa limite extrême, la même que celle de l'Empire Inca (Quechua) de Huayna Capac.

Le vainqueur : Lantaro, le « Vercingétorix » araucun, la voix indienne isolée.

Entre les deux dates : les massacres, les viols, les spoliations, l'exploitation, les virus, les microbes.

Tableau 11

Et maintenant que dirons-nous

Que devons-nous adresser à vos oreilles?

Sommes-nous seulement quelque chose ?....

Guanikana

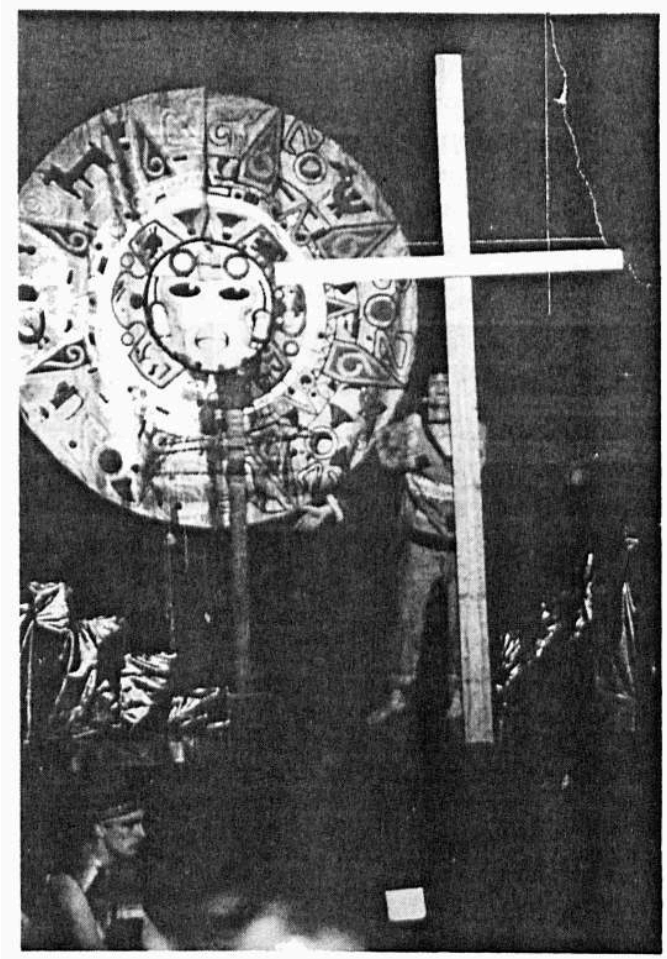

Bertrand PELLETIER

\section{Le pire n'est pas toujours sûr !}

- Pensons à ceux qui ont témoigné du Choc : Las Casas, Sahagun et autres.

- Pensons aux résistants tués, mais non oubliés tel Tupac Amaru à Cuzco. 
- L'extension du Chili a failli anéantir les Araucans, mais maintenant c'est le crépuscule de Pinochet ; les Araucans sont toujours là.

En mai 1992, dans le cadre de la Campagne des 500 ans j'ai entendu une jeune femme, Indienne de l'Alaska, parler des problèmes de sa tribu face aux U.S.A. Elle parlait espagnol pour être entendue d'Indiens du Pérou, de Bolivie, présents aussi. Et maintenant depuis les glaces du Grand Nord jusqu'aux Terres Australes du Chili, se fait entendre la voix indienne collective.

Et puis :

18 Aucune des actrices, aucun des acteurs du Théâtre Universitaire de Franche-Comté n'a parmi ses ancêtres un Aztèque, un Maya, un Aymara, un Quechua. Mais ici en Europe, en France, en Franche-Comté ils font entendre la voix collective des opprimés : celle d'Angela Carmen, l'Indienne de l'Alaska, celle de Léonard Peltier, celle de Rigoberta Menchu, parlant de leur peuple.

Le pire n'est pas toujours sûr

Guanikana

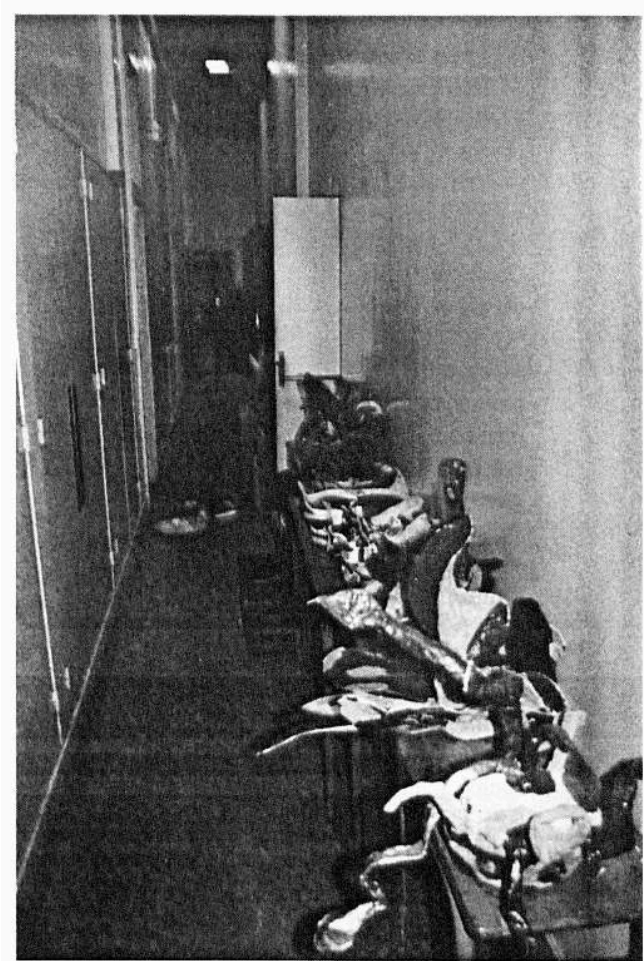

Bertrand PELLETIER 


\section{NOTES}

1. Guanikana est le nom donné par les Indiens à Christophe Colomb lorsqu'il débarqua à Ayti. cf. Anacaona de J. Metellus.

2. L'envers de la conquête, Miguel Léon Portilla, Ed. Federop

Récits aztèques de la conquête, textes choisis et présentés par Georges Baudot et Tzvetan Todorov, Ed. Gallimard.

Les Prophéties du Chilam Balam, présentation de J.M.G. Le Clézio, Ed. Gallimard.

La découverte de l'Amérique, Christophe Colomb, Ed. La découverte.

Anacaona, J. Metellus, Ed. Hatier.

Très brève relation de la destruction des Indes, Bartolomé de Las Casas, Ed. La découverte 